\title{
Analisis Tata Kelola Teknologi Informasi pada Lembaga Kursus dan Pelatihan
}

\author{
Yusup Darmanto ${ }^{* 1}$, M. Suyanto ${ }^{2}$, Sudarmawan ${ }^{3}$ \\ ${ }^{1}$ Mahasiswa MTI STMIK AMIKOM Yogyakarta \\ ${ }^{2,3}$ Dosen MTI STMIK AMIKOM Yogyakarta \\ E-mail: *11 yusupdarmanto@gmail.com, ${ }^{2}$ yanto@ amikom.ac.id, ${ }^{3}$ sudarmawan@amikom.ac.id
}

\begin{abstract}
Abstrak
Perkembangan teknologi informasi yang semakin cepat sangat mempengaruhi kegiatan usaha manusia di bidang apapun khususnya bidang bisnis. Saat ini tidak dapat dipungkiri bahwa informasi menjadi salah satu sumber daya utama pada suatu perusahaan untuk meningkatkan daya saing terhadap para pesaingnya. Oleh sebab itu, setiap perusahaan mencoba untuk menerapkan teknologi informasi agar dapat meningkatkan efektifitas dan efesiensi dalam proses bisnis, hal ini bertujuan agar mampu memberikan nilai tambah yaitu berupa competitive advantage dalam persaingan bisnis.

Banyak hal yang berkaitan dengan pemanfaatan teknologi informasi yang digunakan belum optimal. Maka dari itu penulis berusaha menganalisa kinerja atau kegiatan institusi Lembaga Kursus dan Pelatihan (LKP) tersebut terkait pemanfaatan teknologi informasi, agar dapat memberikan suatu pemikiran yang berdasarkan Best Practices standar COBIT 4.1 sehingga dapat dijadikan bahan pertimbangan dalam mengambil keputusan strategis.

Lembaga Kursus dan Pelatihan (LKP) Terra Computer System dan Adi Wahana Informatika di Kota Kediri telah menerapkan tata kelola teknologi informasi pada level Repeatable but Intuitif. Hasil pengolahan kuesioner mendapati nilai rata-rata untuk domain Plan and Organise (PO) dan Acquire and Implement (AI) adalah antara 1,50 - 2,49 dari rentang nilai 0 sampai 5. Artinya telah melakukan tata kelola teknologi informasi masih cukup baik meskipun belum baku
\end{abstract}

Kata Kunci-COBIT 4.1, Lembaga Kursus dan Pelatihan, Tata Kelola

The development of information technology is growing rapidly affect activity in any field of human endeavor, especially in business. Currently there is no doubt that the information becomes one of the main resources in an enterprise to improve competitiveness against its rivals. Therefore, every company tries to implement information technology in order to improve effectiveness and efficiency in business processes, it aims to be able to provide added value in the form of competitive advantage in business competition.

Many issues related to the utilization of information technology used is not optimal. Thus the authors have attempted to analyze the performance or activities of the institution Course and Training Institute (CTI) is related to the utilization of information technology, in order to give a thought which is based on Best Practices COBIT 4.1 standards so that it can be considered in making strategic decisions.

Courses and Training Institute (CTI) in Kediri have implemented information technology governance at the level of Repeatable but Intuitive. Results of questionnaire processing finds the average value for the domain Plan and organisé (PO) and the Acquire and Implement (AI) is between 1.50 to 2.49 of the value range of 0 to 5. It has been doing information technology governance is still pretty good though not raw.

Keywords - COBIT 4.1, Courses and Training Institute, Governance 


\section{PENDAHULUAN}

Penerapan sistem teknologi informasi akan bermanfaat jika penerapannya sesuai dengan tujuan dari visi dan misi organisasi atau institusi dengan menetapkan strategi bisnis dan strategi sistem teknologi informasi. Sehingga dibutuhkan suatu analisa berbagai faktor yang mempengaruhi terbentuknya suatu perencanaan strategi sistem atau teknologi informasi yang adaptable dan selaras dengan strategi bisnis.[1]

Di kota Kediri banyak Lembaga Kursus dan Pelatihan yang terdaftar di Dinas Pendidikan. Salah satu yang dominan adalah LKP yang bergerak di bidang Teknologi Informasi (Komputer). Secara administratif ada 2 LKP yang sudah memiliki kualifikasi akreditasi A (sesuai Standar Nasional Pendidikan) yaitu LKP TERRA COMPUTER SYSTEM KEDIRI, LKP ADIWAHANA INFORMATIKA. Sedangkan yang berkualifikasi akreditasi B (sesuai Standar Pelayanan Minimal) yaitu LKP LP3I dan LKP DK COMPUTER, LKP MAGISTRA UTAMA.

Dari semua LKP tersebut telah memanfaatkan teknologi informasi dalam menunjang kegiatan bisnis lembaga. Akan tetapi sejauh mana atau seberapa besar penerapan teknologi informasi tersebut mampu menunjang proses bisnis lembaga, masih belum diketahui atau belum terukur dengan baik.

COBIT 4.1 adalah kerangka kerja teknologi informasi yang dipublikasikan oleh ISACA (Information System Audit and Control Association) dirancang agar dapat menjadi alat bantu yang dapat memecahkan permasalahan pada IT governance dalam memahami dan mengelola resiko serta keuntungan yang berhubungan dengan sumber daya informasi organisasi atau institusi.[2]

Dibandingkan dengan model/tools analisis teknologi informasi yang lainnya misalnya ITIL, COSO, ISO/IEC 17799:2005, maka COBIT 4.1 lebih berorientasi bisnis. COBIT 4.1 dirancang untuk digunakan tidak hanya oleh pengguna dan auditor, tetapi juga yang lebih penting, sebagai pedoman yang komprehensif bagi manajemen dan pemilik Business Process.[3]

Analisis dengan Framework COBIT 4.1 ini akan menghasilkan gambaran tentang tata kelola pada proses TI yang berjalan pada instansi tempat penelitian. Dengan perhitungan Maturity Level model COBIT 4.1, hasilnya akan bisa menjadi rujukan dan rekomendasi bagaimana seharusnya tata kelola teknologi informasi dijalankan guna menunjang efektifitas dan efisiensi bisnis, sehingga mampu memberikan nilai tambah berupa Competitive advantage dalam persaingan bisnis.[4]

\section{METODE PENELITIAN}

\subsection{Metodologi Penelitian}

Penelitian ini menggunakan metode deskriptif, meliputi pengumpulan data untuk pengujian hipotesis atau menjawab pertanyaan mengenai status terakhir dari subjek penelitian. Tujuannya adalah untuk dasar pengambilan keputusan dan mengenali perilaku data yang ada saat ini. Penelitian deskriptif adalah metode penelitian yang berusaha menggambarkan objek atau subjek yang diteliti sesuai dengan apa adanya.

\subsection{Metodologi Pengumpulan Data}

Adapun metode atau cara yang digunakan dalam memperoleh dan mengumpulkan data pada penelitian ini adalah sebagai berikut ini:

1) Studi kepustakaan: Pencarian bahan-bahan atau buku-buku bacaan (teori) karya ilmiah dan sumber-sumber bacaan lain yang yang erat kaitannya dengan masalah yang sedang dibahas.

2) Observasi: Pengumpulan data dilakukan dengan datang langsung ke LKP-LKP di Kota Kediri yang sudah berkualifikasi akreditasi A dan sudah menerapkan teknologi informasi 
dalam kegiatan bisnisnya, untuk mendapatkan informasi yang menjadi sumber utama penelitian. Dalam survei tersebut akan dilakukan dengan penyebaran kuisioner dan wawancara dengan pihak-pihak yang berkepentingan.

3) Melakukan dokumentasi pada data-data, peraturan-peraturan penyelenggaraan pendidikan kursus, dan profil lembaga.

\section{HASIL DAN PEMBAHASAN}

Dalam menentukan domain COBIT yang digunakan untuk analisis pada LKP-LKP di Kota Kediri, penulis menentukan secara langsung pada Domain Plan and Organise (PO) dan Acquire And Implement (AI), sedangkan penentuan pada proses kinerja TI pada Domain PO yang meliputi PO1, PO2, PO3 dan PO7, serta Domain AI yang meliputi AI-1, AI-2 dan AI-3, tersebut berdasarkan tinjauan langsung ke tempat penelitian, dalam hal ini dengan wawancara kepada manajemen, kepada bagian yang menangani perangkat teknologi informasi dan pengisian kuisener Management Awareness.

\section{Tahap-Tahap Analisis Tata Kelola TI}

\subsection{Observasi dan Telaah Dokumen Lembaga}

Proses ini dilakukan dengan meninjau profil perusahan sebagai objek yang akan diteliti. Peninjauan dilakukan melalui penggalian dokumen-dokumen fisik, serta wawancara dengan pihak manajemen (Direktur/Pimpinan), dan TI Manage.

\subsection{Penentuan Obyek Proses Domain PO dan AI}

Kegiatan pemilihan proses TI dari proses-proses TI yang terdapat dalam domain tersebut, didasarkan pada tingkat kepentingan proses. Informasi mengenai tingkat kepentingan ini, didapatkan dari pihak terkait menggunakan Kuisioner Management Awareness Diagnostic. Sebagaimana tabel 1 di bawah ini:

Tabel 1. Kuisener Management Awareness Domain Plan and Organise (PO)[5]

\begin{tabular}{|c|c|c|c|c|c|c|}
\hline \multirow{3}{*}{ Kode } & \multirow{3}{*}{ Proses } & \multicolumn{5}{|c|}{$\begin{array}{l}\text { Seberapa penting proses } \\
\text { Tersebut bagi tujuan bisnis }\end{array}$} \\
\hline & & 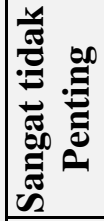 & 然 & 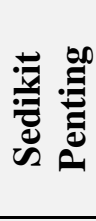 & ع & 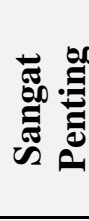 \\
\hline & & 1 & 2 & 3 & 4 & 5 \\
\hline PO1 & $\begin{array}{l}\text { Define a Strategic IT Plan } \\
\text { Mendefinisikan rencana strategis TI }\end{array}$ & & & & & $\sqrt{ }$ \\
\hline PO2 & $\begin{array}{l}\text { Define the Information Architecture } \\
\text { Mendefinisikan arsitektur informasi }\end{array}$ & & & & & $\sqrt{ }$ \\
\hline PO3 & $\begin{array}{l}\text { Determine Technological Direction } \\
\text { Menentukan arahan teknologi }\end{array}$ & & & & & $\sqrt{ }$ \\
\hline PO4 & $\begin{array}{l}\text { Define the IT Processes, Organisation and } \\
\text { Relationship } \\
\text { Mendefinisikan proses TI, organisasi dan } \\
\text { keterhubungannya }\end{array}$ & & & & $\sqrt{ }$ & \\
\hline PO5 & $\begin{array}{l}\text { Manage the IT Investment } \\
\text { Mengelola investasi TI }\end{array}$ & & & $\sqrt{ }$ & & \\
\hline
\end{tabular}


Citec Journal, Vol. 1, No. 2, Februari 2014 - April 2014

Tabel 1. Lanjutan

\begin{tabular}{|c|l|l|l|l|l|l|}
\hline PO6 & $\begin{array}{l}\text { Communicate Management Aims and Direction } \\
\text { Mengkomunikasikan tujuan dan arahan } \\
\text { manajemen }\end{array}$ & & $\sqrt{ }$ & & \\
\hline PO7 & $\begin{array}{l}\text { Manage IT Human Resources } \\
\text { Mengelola sumber daya TI }\end{array}$ & & & & $\sqrt{ }$ \\
\hline PO8 & $\begin{array}{l}\text { Manage Quality } \\
\text { Mengelola kualitas }\end{array}$ & & & \\
\hline PO9 & $\begin{array}{l}\text { Assess and Manage IT Risks } \\
\text { Menaksir dan mengelola resiko TI }\end{array}$ & & $\sqrt{ }$ & & & \\
\hline PO10 & $\begin{array}{l}\text { Manage Projects } \\
\text { Mengelola proyek }\end{array}$ & $\sqrt{ }$ & & \\
\hline
\end{tabular}

Tabel 2. Kuisener Management Awareness Domain Acquire and Implement (AI)[5]

\begin{tabular}{|c|c|c|c|c|c|c|}
\hline \multirow{3}{*}{ Kode } & \multirow{3}{*}{ Proses } & \multicolumn{5}{|c|}{$\begin{array}{l}\text { Seberapa penting proses } \\
\text { Tersebut bagi tujuan bisnis }\end{array}$} \\
\hline & & 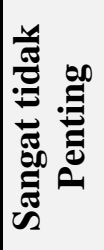 & 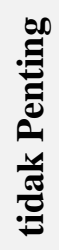 & 是 & : & 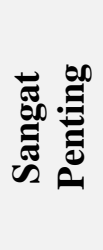 \\
\hline & & 1 & 2 & 3 & 4 & 5 \\
\hline AI1 & $\begin{array}{l}\text { Identify Automated Solutions } \\
\text { Mengidentifikasi solusi otomatis }\end{array}$ & & & & & $\sqrt{ }$ \\
\hline AI2 & $\begin{array}{l}\text { Acquire and Maintain Application Software } \\
\text { Memperoleh dan memelihara software aplikasi }\end{array}$ & & & & & $\sqrt{ }$ \\
\hline AI3 & $\begin{array}{l}\text { Acquire and Maintain Technology } \\
\text { Infrastructure } \\
\text { Memperoleh dan memelihara infrastruktur } \\
\text { teknologi }\end{array}$ & & & & & $\sqrt{ }$ \\
\hline AI4 & $\begin{array}{l}\text { Enable Operation and Use } \\
\text { Memungkinkan operasional dan penggunaan }\end{array}$ & & & $\sqrt{ }$ & & \\
\hline AI5 & $\begin{array}{l}\text { Procure IT Resources } \\
\text { Memenuhi sumber daya TI }\end{array}$ & & & $\sqrt{ }$ & & \\
\hline AI6 & $\begin{array}{l}\text { Manage Changes } \\
\text { Mengelola perubahan }\end{array}$ & & & $\sqrt{ }$ & & \\
\hline AI7 & $\begin{array}{l}\text { Install and Accredit Solutions and Changes } \\
\text { Instalasi dan akreditasi solusi beserta } \\
\text { perubahaannya }\end{array}$ & & $\sqrt{ }$ & & & \\
\hline
\end{tabular}

Dari setiap proses teknologi informasi terdapat Detailed Control Objectives yang merupakan alat kontrol dari proses teknologi informasi itu sendiri.

Berdasarkan hasil Kuisener Management Awareness di atas maka penelitian akan dilakukan terhadap Detailed Control Objectives dari domain PO dan AI sebagai berikut: 
Tabel 3. IT Process Control Objective Domain PO [5]

\begin{tabular}{|l|l|}
\hline \multicolumn{2}{|l|}{ COBIT Control Objectives } \\
\hline \multicolumn{2}{|l|}{ Plan and Organise (PO) } \\
\hline PO1. Define a strategic IT plan \\
\hline PO1.1 & IT Value Management \\
\hline PO1.2 & Business-IT Alignment \\
\hline PO1.3 & Assessment of Current Capability and Performance \\
\hline PO1.4 & IT Strategic Plan \\
\hline PO1.5 & IT tactical Plans \\
\hline PO1.6 & IT Portfolio management \\
\hline PO2.Define the Information Architecture \\
\hline PO2.1 & Enterprise Information Architecture Model \\
\hline PO2.2 & Enterprise Data Dictionary and Data Syntax Rules \\
\hline PO2.3 & Data Classification Scheme \\
\hline PO2.4 & Integrity Management \\
\hline PO3.Determine Technological Direction \\
\hline PO3.1 & Technological Direction Planning \\
\hline PO3.2 & Technology Infrastructure Plan \\
\hline PO3.3 & Monitor Future Trends and Regulations \\
\hline PO3.4 & Technology Standards \\
\hline PO3.5 & IT Architecture Board \\
\hline PO7.Manage IT Human Resources \\
\hline PO7.1 & Personnel Recruitment and Retention \\
\hline PO7.2 & Personnel Competencies \\
\hline PO7.3 & Staffing of Roles \\
\hline PO7.4 & Personnel Training \\
\hline PO7.5 & Dependence Upon Individuals \\
\hline PO7.6 & Personnel Clearance Procedures \\
\hline PO7.7 & Employee Job Performance Evaluation \\
\hline PO7.8 & Job Change and Termination \\
\hline
\end{tabular}


Citec Journal, Vol. 1, No. 2, Februari 2014 - April 2014

Tabel 4. IT Process Control Objective Domain AI [5]

\begin{tabular}{|l|l|}
\hline \multicolumn{2}{|l|}{ COBIT Control Objectives } \\
\hline Acquire and Implement (AI) \\
\hline AI1. Identify automated solutions \\
\hline AI1.1 & $\begin{array}{l}\text { Definition and maintenance of business functional and } \\
\text { technical }\end{array}$ \\
\hline AI1.2 & Risk analysis report \\
\hline AI1.3 & $\begin{array}{l}\text { Feasibility study and formulation of alternative courses of } \\
\text { action }\end{array}$ \\
\hline AI1.4 & Requirement and feasibility decision and approval \\
\hline AI2. Acquire and maintain application software \\
\hline AI2.1 & High-level design \\
\hline AI2.2 & Detailed design \\
\hline AI2.3 & Application kontrol and auditability \\
\hline AI2.4 & Application security and availability \\
\hline AI2.5 & $\begin{array}{l}\text { Configuration and implementation of acquired application } \\
\text { software }\end{array}$ \\
\hline AI2.6 & Major upgrades to existing sistems \\
\hline AI2.7 & Development of application software \\
\hline AI2.8 & Software quality assurance \\
\hline AI2.9 & Application requirements management \\
\hline AI2.10 & Application software maintenance \\
\hline AI3. Acquire and maintain technology infrastructure \\
\hline AI3.1 & Technological infrastructure acquisition plan \\
\hline AI3.2 & Infrastructure resource protection and availability \\
\hline AI3.3 & Infrastructure maintenance \\
\hline AI3.4 & Feasibility test environment \\
\hline
\end{tabular}

\subsection{Analisis Data Domain PO dan AI}

Setelah dilakukan pengolahan data, penulis melakukan analisis data. Analisis data yang dilakukan terdiri dari analisis tingkat kematangan saat ini, tingkat kematangan yang diharapkan dan analisis kesenjangan.

\subsubsection{Analisis Kematangan/Kedewasaan Saat Ini (As Is)}

Analisis yang dilakukan pada tahap ini adalah analisis untuk menilai tingkat kematangan tata kelola teknologi informasi untuk proses PO dan AI saat ini (as-is). Pada tahap analisis tingkat kematangan tata kelola teknologi saat ini (as- is), penulis melakukan penilaian terhadap masing-masing atribut model kematangan untuk proses yang akan dinilai [6].

Setelah masing-masing atribut model kematangan untuk proses tersebut memperoleh penilaian, maka penulis akan menggabungkan seluruh nilai atribut proses tersebut untuk mendapatkan tingkat kematangan tata kelola teknologi informasi untuk proses tersebut pada saat ini (as-is). 


\subsubsection{Domain Plan and Organize (PO)}

Tabel 5. Hasil Perhitungan Tingkat Maturity Level Plan and Organize (Perencanaan dan Organisasi) LKP Terra Computer System Kediri

\begin{tabular}{|c|c|l|c|l|}
\hline No. & Kode & \multicolumn{1}{|c|}{ Proses } & Hasil & $\begin{array}{c}\text { Tingkat } \\
\text { Maturity }\end{array}$ \\
\hline 1 & PO1 & $\begin{array}{l}\text { PO1 Define a Strategic IT Plan (Membuat } \\
\text { Perencanaan Strategis di Bidang TI) }\end{array}$ & 1,83 & $\begin{array}{l}\text { Repeatable } \\
\text { but Intuitif }\end{array}$ \\
\hline 2 & PO2 & $\begin{array}{l}\text { PO2 Define the Information Architecture } \\
\text { (Membuat Arsitektur Informasi) }\end{array}$ & 1,25 & Initial \\
\hline 3 & PO3 & $\begin{array}{l}\text { PO3 Determine Technological Direction } \\
\text { (Menentukan Arah Teknologi) }\end{array}$ & 2,40 & $\begin{array}{l}\text { Repeatable } \\
\text { but Intuitif }\end{array}$ \\
\hline 4 & PO7 & $\begin{array}{l}\text { PO7 Manage IT Human Resources } \\
\text { (Mengatur Sumber Daya Manusia TI) }\end{array}$ & 2,63 & Defined \\
\hline \multicolumn{2}{|c|}{ Rata-rata domain PO } & 2,03 & $\begin{array}{l}\text { Repeatable } \\
\text { but Intuitif }\end{array}$ \\
\hline
\end{tabular}

Tabel 6. Hasil Perhitungan Tingkat Maturity Level Plan and Organize (Perencanaan dan Organisasi) LKP Adiwahana Informatika Kediri

\begin{tabular}{|c|c|l|c|c|}
\hline No. & Kode & \multicolumn{1}{|c|}{ Proses } & Hasil & $\begin{array}{c}\text { Tingkat } \\
\text { Maturity }\end{array}$ \\
\hline 1 & PO1 & $\begin{array}{l}\text { PO1 Define a Strategic IT Plan (Membuat } \\
\text { Perencanaan Strategis di Bidang TI) }\end{array}$ & 2,00 & $\begin{array}{l}\text { Repeatable } \\
\text { but Intuitif }\end{array}$ \\
\hline 2 & PO2 & $\begin{array}{l}\text { PO2 Define the Information Architecture } \\
\text { (Membuat Arsitektur Informasi) }\end{array}$ & 1,50 & $\begin{array}{l}\text { Repeatable } \\
\text { but Intuitif }\end{array}$ \\
\hline 3 & PO3 & $\begin{array}{l}\text { PO3 Determine Technological Direction } \\
\text { (Menentukan Arah Teknologi) }\end{array}$ & 2,40 & $\begin{array}{l}\text { Repeatable } \\
\text { but Intuitif }\end{array}$ \\
\hline 4 & PO7 & $\begin{array}{l}\text { PO7 Manage IT Human Resources } \\
\text { (Mengatur Sumber Daya Manusia TI) }\end{array}$ & 2,63 & Defined \\
\hline & Rata-rata domain PO & 2,13 & $\begin{array}{l}\text { Repeatable } \\
\text { but Intuitif }\end{array}$ \\
\hline
\end{tabular}

\subsubsection{Domain Acquire and Implement (AI)}

Tabel 7. Hasil Perhitungan Tingkat Maturity Level Acquire and Implement (Pengadaan dan Implementasi) LKP Terra Computer System Kediri

\begin{tabular}{|c|c|l|c|c|}
\hline No. & Kode & \multicolumn{1}{|c|}{ Proses } & Hasil & $\begin{array}{c}\text { Tingkat } \\
\text { Maturity }\end{array}$ \\
\hline 1 & AI1 & $\begin{array}{l}\text { AI1 Identify Automated Solution } \\
\text { (Mengidentifikasikan solusi otomatis) }\end{array}$ & 2,00 & $\begin{array}{c}\text { Repeatable } \\
\text { but Intuitif }\end{array}$ \\
\hline 2 & AI2 & $\begin{array}{l}\text { AI2 Acquire and Maintain Application } \\
\text { (Mendapatkan dan Menjaga Aplikasi) }\end{array}$ & 1,40 & Initial \\
\hline 3 & AI3 & $\begin{array}{l}\text { AI3 Acquire and Maintain Technology } \\
\text { Infrastructure (Mendapatkan dan } \\
\text { Memelihara Infrastruktur Teknologi) }\end{array}$ & 1,50 & $\begin{array}{c}\text { Repeatable } \\
\text { but Intuitif }\end{array}$ \\
\hline & Rata-rata Domain AI & 1,63 & $\begin{array}{c}\text { Repeatable } \\
\text { but Intuitif }\end{array}$ \\
\hline
\end{tabular}


Citec Journal, Vol. 1, No. 2, Februari 2014 - April 2014

Tabel 8. Hasil Perhitungan Tingkat Maturity Level Acquire and Implement (Pengadaan dan Implementasi) LKP Adiwahana Informatika Kediri

\begin{tabular}{|c|c|l|c|c|}
\hline No. & Kode & \multicolumn{1}{|c|}{ Proses } & Hasil & $\begin{array}{c}\text { Tingkat } \\
\text { Maturity }\end{array}$ \\
\hline 1 & AI1 & $\begin{array}{l}\text { AI1 Identify Automated Solution } \\
\text { (Mengidentifikasikan solusi otomatis) }\end{array}$ & 2,00 & $\begin{array}{c}\text { Repeatable } \\
\text { but Intuitif }\end{array}$ \\
\hline 2 & AI2 & $\begin{array}{l}\text { AI2 Acquire and Maintain Application } \\
\text { (Mendapatkan dan Menjaga Aplikasi) }\end{array}$ & 1,40 & Initial \\
\hline 3 & AI3 & $\begin{array}{l}\text { AI3 Acquire and Maintain Technology } \\
\text { Infrastructure (Mendapatkan dan } \\
\text { Memelihara Infrastruktur Teknologi) }\end{array}$ & 1,50 & $\begin{array}{l}\text { Repeatable } \\
\text { but Intuitif }\end{array}$ \\
\hline \multicolumn{3}{|c|}{ Rata-rata Domain AI } & 1,63 & $\begin{array}{c}\text { Repeatable } \\
\text { but Intuitif }\end{array}$ \\
\hline
\end{tabular}

Dari perhitungan data tersebut di atas, rata-rata tingkat kedewasaan (Maturity Level) untuk masing-masing lembaga adalah sebagai berikut:

Tabel 9. Hasil Perhitungan Rata-rata Tingkat Maturity Level Plan and Organize (Perencanaan dan Organisasi) dan Acquire and Implement (Pengadaan dan Implementasi) LKP Terra Computer System Kediri

\begin{tabular}{|c|c|l|c|l|}
\hline No. & Kode & \multicolumn{1}{|c|}{ Proses } & Hasil & $\begin{array}{c}\text { Tingkat } \\
\text { Maturity }\end{array}$ \\
\hline 1 & PO1 & $\begin{array}{l}\text { PO1 Define a Strategic IT Plan (Membuat } \\
\text { Perencanaan Strategis di Bidang TI) }\end{array}$ & 1,83 & $\begin{array}{l}\text { Repeatable } \\
\text { but Intuitif }\end{array}$ \\
\hline 2 & PO2 & $\begin{array}{l}\text { PO2 Define the Information Architecture } \\
\text { (Membuat Arsitektur Informasi) }\end{array}$ & 1,25 & Initial \\
\hline 3 & PO3 & $\begin{array}{l}\text { PO3 Determine Technological Direction } \\
\text { (Menentukan Arah Teknologi) }\end{array}$ & 2,40 & $\begin{array}{l}\text { Repeatable } \\
\text { but Intuitif }\end{array}$ \\
\hline 4 & PO7 & $\begin{array}{l}\text { PO7 Manage IT Human Resources } \\
\text { (Mengatur Sumber Daya Manusia TI) }\end{array}$ & 2,63 & Defined \\
\hline 5 & AI1 & $\begin{array}{l}\text { AI1 Identify Automated Solution } \\
\text { (Mengidentifikasikan solusi otomatis) }\end{array}$ & 2,00 & $\begin{array}{l}\text { Repeatable } \\
\text { but Intuitif }\end{array}$ \\
\hline 6 & AI2 & $\begin{array}{l}\text { AI2 Acquire and Maintain Application } \\
\text { (Mendapatkan dan Menjaga Aplikasi) }\end{array}$ & 1,40 & Initial \\
\hline 7 & AI3 & $\begin{array}{l}\text { AI3 Acquire and Maintain Technology } \\
\text { Infrastructure (Mendapatkan dan } \\
\text { Memelihara Infrastruktur Teknologi) }\end{array}$ & 1,50 & $\begin{array}{l}\text { Repeatable } \\
\text { but Intuitif }\end{array}$ \\
\hline & $\begin{array}{l}\text { Rata-rata domain PO dan AI } \\
\text { Repeatable } \\
\text { but Intuitif }\end{array}$ \\
\hline
\end{tabular}


Tabel 10. Hasil Perhitungan Rata-rata Tingkat Maturity Level Plan and Organize (Perencanaan dan Organisasi) dan Acquire and Implement (Pengadaan dan Implementasi)

LKP Adiwahana Informatika Kediri

\begin{tabular}{|c|c|c|c|c|}
\hline No. & Kode & Proses & Hasil & $\begin{array}{l}\text { Tingkat } \\
\text { Maturity }\end{array}$ \\
\hline 1 & PO1 & $\begin{array}{l}\text { PO1 Define a Strategic IT Plan (Membuat } \\
\text { Perencanaan Strategis di Bidang TI) }\end{array}$ & 2,00 & $\begin{array}{l}\text { Repeatable } \\
\text { but Intuitif }\end{array}$ \\
\hline 2 & $\mathrm{PO} 2$ & $\begin{array}{l}\text { PO2 Define the Information Architecture } \\
\text { (Membuat Arsitektur Informasi) }\end{array}$ & 1,50 & $\begin{array}{l}\text { Repeatable } \\
\text { but Intuitif }\end{array}$ \\
\hline 3 & PO3 & $\begin{array}{l}\text { PO3 Determine Technological Direction } \\
\text { (Menentukan Arah Teknologi) }\end{array}$ & 2,40 & $\begin{array}{l}\text { Repeatable } \\
\text { but Intuitif }\end{array}$ \\
\hline 4 & PO7 & $\begin{array}{l}\text { PO7 Manage IT Human Resources } \\
\text { (Mengatur Sumber Daya Manusia TI) }\end{array}$ & 2,63 & Defined \\
\hline 5 & AI1 & $\begin{array}{l}\text { AI1 Identify Automated Solution } \\
\text { (Mengidentifikasikan solusi otomatis) }\end{array}$ & 2,00 & $\begin{array}{l}\text { Repeatable } \\
\text { but Intuitif }\end{array}$ \\
\hline 6 & AI2 & $\begin{array}{l}\text { AI2 Acquire and Maintain Application } \\
\text { (Mendapatkan dan Menjaga Aplikasi) }\end{array}$ & 1,40 & Initial \\
\hline 7 & AI3 & $\begin{array}{l}\text { AI3 Acquire and Maintain Technology } \\
\text { Infrastructure (Mendapatkan dan } \\
\text { Memelihara Infrastruktur Teknologi) }\end{array}$ & 1,50 & $\begin{array}{l}\text { Repeatable } \\
\text { but Intuitif }\end{array}$ \\
\hline \multicolumn{3}{|r|}{ Rata-rata domain $\mathrm{PO}$ dan $\mathrm{AI}$} & 1,92 & $\begin{array}{l}\text { Repeatable } \\
\text { but Intuitif }\end{array}$ \\
\hline
\end{tabular}

Dari hasil perhitungan diperoleh rata-rata nilai domain tata kelola teknologi informasi pada Lembaga Kursus dan Pelatihan (LKP) di Kota Kediri berkisar pada nilai 1,50-2,49. Dari nilai ini dapat tarik kesimpulan bahwa pengelolaan teknologi informasi dilakukan secara Repeatable but Intuitif artinya pada level ini, proses dikembangkan ke dalam tahapan yang prosedur serupa diikuti oleh pihak-pihak yang berbeda untuk pekerjaan yang sama. Tidak terdapat pelatihan formal atau pengkomunikasian prosedur standar dan tanggung jawab diserahkan kepada individu masing-masing. Terdapat tingkat kepercayaan yang tinggi terhadap pengetahuan individu sehingga kemungkinan kesalahan/error bisa terjadi.

Meskipun demikian tata kelola pada LKP di kota Kediri masih rendah pada level kematangan. Level ini masih pada transisi antara Repeatable but Intuitive menuju Defined Process. Masih dibutuhkan banyak perbaikan yang harus dilakukan pada domain PO dan AI terutama pada sub domain PO1, PO2, AI2 karena ke tiga domain ini masih pada level Repeatable but Intuitive artinya pada level ini, kebijakan untuk mengatur pengembangan suatu proyek dan prosedur dalam mengimplementasikan kebijakan tersebut belum ditetapkan seluruhnya. Tingkat efektif suatu proses manajemen dalam mengembangankan proyek adalah dilembagakan, dengan memungkinkan organisasi untuk mengulangi pengalaman yang berhasil. Tingkat efektif suatu proses mempunyai karakteristik seperti; practiced, dokumentasi, enforced, trained, measured, dan dapat ditingkatkan [7].

\subsubsection{Analisis Tingkat Kematangan yang diharapkan (to-be)}

Penilaian tingkat kematangan yang diharapkan (to-be) bertujuan untuk memberikan acuan untuk pengembangan tata kelola teknologi informasi di lembaga tersebut. Sama seperti pada tahap analisis tingkat kematangan saat ini (as-is), penulis melakukan analisis tingkat kematangan tata kelola teknologi informasi yang diharapkan lembaga, berdasarkan nilai masing- masing atribut model kematangan untuk proses yang dinilai dan hasil wawancara dengan pihak LKP. 
Citec Journal, Vol. 1, No. 2, Februari 2014 - April 2014

\subsubsection{Analisis Tingkat Nilai Kesenjangan Kematangan Saat ini}

Setelah menilai dan mengetahui tingkat kematangan tata kelola saat ini berkisar pada nilai 1,50 - 2,49, maka dilakukan analisis kesenjangan terhadap tingkat kematangan yang diharapkan yaitu sebesar 2,5. Analisa ini diharapkan dapat memberikan kemudahan bagai pengelolaan teknologi informasi yang serasi diantara ke-4 domain.

Alasan nilai yang ingin dicapai sebesar 2, 5 adalah melihat kesiapan lembaga dalam tata kelola manajemen, pengelolaan SDM dan Keuangan. Tabel 11 dan 12 di bawah ini menunjukkan gap antara tingkat kematangan saat ini dengan tingkat kematangan yang diharapkan:

Tabel 11. Perbandingan Tingkat Kematangan Saat ini dan Tingkat Kematangan Yang Diharapkan LKP Terra Computer System Kediri

\begin{tabular}{|c|c|c|c|}
\hline Domain & \multicolumn{3}{|c|}{ Tingkat Kematangan } \\
\hline & Saat Ini & Diharapkan & Gap (Diharapkan-Saat ini) \\
\hline PO & 2,03 & 2,50 & $2,50-2,03=0,47$ \\
\hline AI & 1,63 & 2,50 & $2,50-1,63=0,87$ \\
\hline \multicolumn{3}{|c|}{ Rata-rata } & $(0,47+0,87) / 2=0,67$ \\
\hline
\end{tabular}

Tabel 12. Perbandingan Tingkat Kematangan Saat ini dan Tingkat Kematangan Yang Diharapkan LKP Adiwahana Informatika Kediri

\begin{tabular}{|c|c|c|c|}
\hline Domain & \multicolumn{3}{|c|}{ Tingkat Kematangan } \\
\hline & Saat Ini & Diharapkan & Gap (Diharapkan-Saat ini) \\
\hline PO & 2,13 & 2,50 & $2,50-2,13=0,37$ \\
\hline AI & 1,63 & 2,50 & $2,50-1,63=0,87$ \\
\hline \multicolumn{3}{|c|}{} & Rata-rata \\
\hline
\end{tabular}

Terdapat Jarak 0.6 pada domain PO dan AI, antara kondisi yang diharapkan dengan kondisi saat ini sebagaimana gambar 1 di bawah ini:

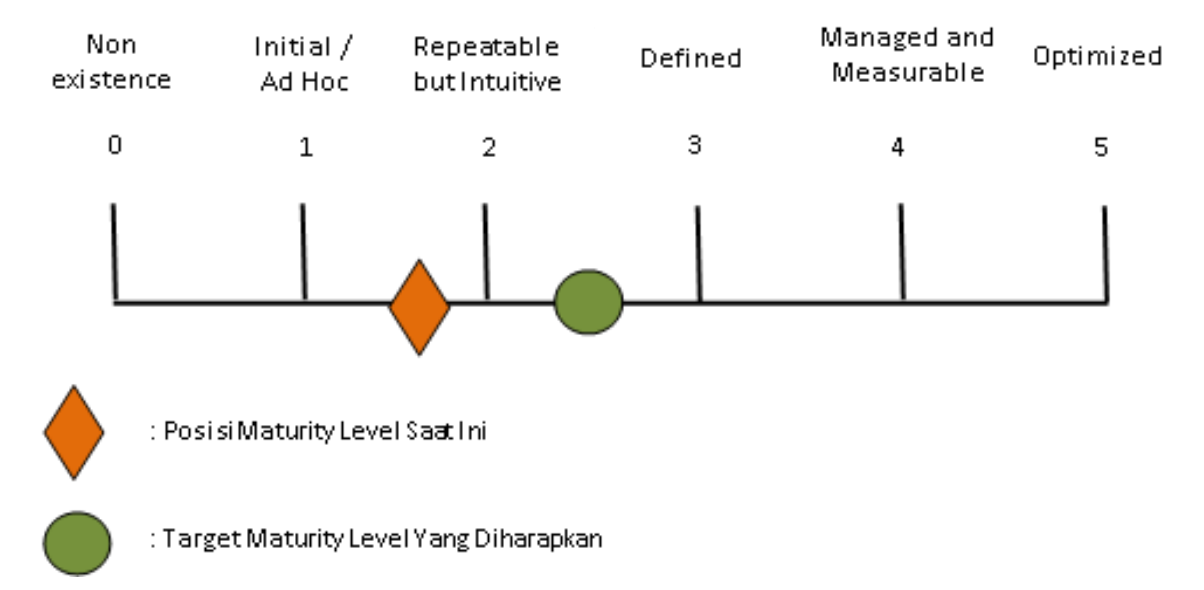

Gambar 1. Model Kedewasaan (Maturity Level) (Sumber: IT Governance Institute, 2007)[5]

Walaupun gap terbilang kecil tetapi dibutuhkan penyesuaian masing-masing domain karena nilai 0.6 adalah nilai rata-rata perdomain, maka penulis akan memberikan rekomendasi pada masing masing domain sehingga perbaikan lebih fokus pada bagian domain yang lemah. 


\subsubsection{Temuan Masalah dan Rekomendasi Perbaikan}

Berdasarkan hasil analisis yang telah dilakukan pada Lembaga Kursus dan Pelatihan di Kota Kediri, maka nilai-nilai temuan akan dicocokan pada kondisi kematangan pada masingmasing domain COBIT 4.1 dari hasil itu dianalisis temuan masalah dan rekomendasi sebagai berikut:

\subsubsection{PO1. Define a Strategic IT Plan}

Tergolong dalam Repeatable but Intuitif dengan kondisi:

a. Lembaga Kursus dan Pelatihan (LKP) di Kota Kediri mengetahui kapan menetapkan perencanaan strategis teknologi informasi.

b. Perencanaan strategis TI dibagi dengan manajemen bisnis dengan berbasis pada kebutuhan.

c. Perbaikan terhadap rencana TI dilakukan dalam merespon permintaan manajemen.

d. Keputusan strategis digerakkan dalam sebuah projek tanpa adanya konsistensi terhadap keseluruhan strategi organisasi. Resiko dan keuntungan yang didapatkan dari keputusan strategis, diketahui dengan cara intuitif.

Temuan Masalah:

a. Lembaga Kursus dan Pelatihan (LKP) di Kota Kediri belum melakukan pembahasan rencana teknologi informasi secara khusus pada pertemuan manajemen bisnis.

b. Perencanaan strategis teknologi informasi belum mengikuti pendekatan terstruktur dan belum didokumentasikan sehingga sulit disosialisasikan kepada semua staf, dan jika ada sosialisasi membutuhkan waktu yang lama.

c. Strategi teknologi informasi secara keseluruhan belum mencakup definisi yang konsisten terhadap risiko sehingga organisasi belum siap mengelola risiko.

Rekomendasi Jangka Pendek (2014-2015):

a. Melakukan pembahasan rencana pengembangan, pengadaan alat baru, atau pelatihan staf teknologi informasi secara khusus.

b. Melakukan perencanaan strategis teknologi informasi mengikuti pendekatan terstruktur dan didokumentasikan kepada semua staf.

c. Menyusun strategi teknologi informasi secara keseluruhan dan menganalisis kemungkinan risiko-risiko yang mungkin terjadi.

\subsubsection{PO2. Define the Information Architecture}

Masih tergolong dalam tata kelola Repeatable but Intuitive dengan kondisi:

a. Sebuah proses informasi arsitektur muncul dan serupa, meskipun informal dan intuitif.

b. $\quad$ Prosedur yang diikuti oleh individu yang berbeda dalam organisasi.

c. Staf memperoleh keterampilan dalam membangun arsitektur informasi melalui pengalaman dan penerapan berulang.

d. Persyaratan taktis mendorong pengembangan komponen arsitektur informasi dengan anggota staf secara individu.

Temuan Masalah:

a. Pelatihan formal masih didasarkan atas inisiatif individu.

b. Prosedur, alat dan teknik, walaupun tidak canggih, belum semua distandarisasi dan didokumentasikan.

c. Komunikasi belum dilakukan secara konsisten terhadap semua staff. 


\section{Rekomendasi:}

a. Jangka Pendek (2014-2015)

i) Melakukan pelatihan secara formal, menyusun jadwal pelatihan.

ii) Menyusun satu bentuk form pelaporan sehingga komunikasi dapat dilakukan secara konsisten memiliki standar pelaporan

b. Jangka Menengah (2015-2017):

i) Mendokumentasikan seluruh prosedur dan alat sehingga tidak ada ketergantungan hanya pada satu ahli.

\subsubsection{AI2. Acquire and Maintain Apllication Software}

Masih tergolong dalam tata kelola Initial dengan kondisi:

a. Ada kesadaran bahwa proses untuk mendapatkan dan mempertahankan aplikasi yang diperlukan. Pendekatan untuk mendapatkan dan mempertahankan perangkat lunak aplikasi bervariasi dari proyek ke proyek.

b. Beberapa solusi individu untuk kebutuhan bisnis tertentu cenderung telah diperoleh secara independen, menghasilkan inefisiensi dengan perawatan dan dukungan.

Temuan Masalah:

a. Lembaga tidak melakukan analisis dan penilaian dalam pengembangan, pengendalian dan pemeliharaan perangkat.

b. Lembaga belum sepenuhnya bekerjasama dengan pihak ke tiga untuk mendapatkan jaminan kualitas TI.

Rekomendasi:

a. Jangka Pendek (2014-2015)

i) Melakukan pembenahan dengan menyusun jadwal pemeliharaan perangkat dan membuat kartu kendali untuk perangkat TI.

b. Jangka Menengah (2015-2017)

i) Bekerjasama dengan pihak ke tiga untuk program penilaiaan dan jaminan kualitas teknologi informasi.

\section{KESIMPULAN}

Berdasarkan hasil penelitian yang telah dilakukan maka dapat ditarik kesimpulan sebagai berikut:

1. Lembaga Kursus dan Pelatihan (LKP) Terra Computer System dan Adi Wahana Informatika di Kota Kediri telah menerapkan tata kelola teknologi informasi pada level Repeatable but Intuitif. Dengan nilai rata-rata untuk domain Plan and Organise (PO) dan Acquire and Implement (AI) adalah antara 1,50-2,49 dari rentang nilai 0 sampai 5. Artinya LKP telah melakukan tata kelola teknologi informasi cukup baik meskipun belum baku. Selain itu dari hasil penelitian menemukan kelemahan terdapat pada subdomain PO1, PO2, dan AI2. Dari ke tiga domain ini ada yang hanya mampu memperoleh nilai rata rata 1,25 dan 1,40 artinya masih pada level Initial. Disamping itu ditemukan beberapa kelemahan yang cukup fatal yaitu tingginya ketergantungan LKP terhadap satu ahli, risiko tidak 
dikelola dengan baik, belum melakukan evaluasi terhadap kepuasan mutu, dokumentasi belum dilakukan dibeberapa bidang teknologi informasi, prosedur dan kebijakan belum dilakukan dengan sungguh-sungguh

2. Dari hasil analisa ada beberapa rekomendasi untuk LKP Terra Computer System Kediri dan Adiwahana Informatika dimana rekomendasi tersebut diberikan berkaitan pada bagian domain yang lemah sehingga perbaikan lebih fokus, sebagai berikut:

a. POI. Define a strategic IT plan

Tergolong dalam Repeatable but Intuitif dengan rekomendasi sebagai berikut:

Jangka Pendek (2014-2015):

i) Melakukan pembahasan rencana pengembangan, pengadaan alat baru, atau pelatihan staf teknologi informasi secara khusus.

ii) Melakukan perencanaan strategis teknologi informasi mengikuti pendekatan terstruktur dan didokumentasikan kepada semua staf.

iii) Menyusun strategi teknologi informasi secara keseluruhan dan menganalisis kemungkinan risiko-risiko yang mungkin terjadi.

b. PO2. Define the Information Architecture

Masih tergolong dalam tata kelola Repeatable but Intuitive dengan rekomendasi sebagai berikut:

Jangka Pendek (2014-2015):

i) Melakukan pelatihan secara formal, menyusun jadwal pelatihan.

ii) Menyusun satu bentuk form pelaporan sehingga komunikasi dapat dilakukan secara konsisten memiliki standar pelaporan.

Jangka Menengah (2015-2017):

i) Mendokumentasikan seluruh prosedur dan alat sehingga tidak ada ketergantungan hanya pada satu ahli.

c. AI2. Acquire and Maintain Application Software

Masih tergolong dalam tata kelola Initial dengan dengan rekomendasi sebagai berikut:

Jangka Pendek (2014-2015):

i) Melakukan pembenahan dengan menyusun jadwal pemeliharaan perangkat dan membuat kartu kendali untuk perangkat TI

Jangka Menengah (2015-2017):

i) Bekerjasama dengan pihak ke tiga untuk program penilaiaan dan jaminan kualitas teknologi informasi

\section{SARAN}

Dari penelitian yang telah dilakukan, penulis memberikan beberapa saran-saran yang nantinya dapat digunakan oleh Lembaga Kursus dan Pelatihan (LKP) Terra Computer System Kediri dan Adiwahana Informatika Kota Kediri untuk memperbaiki tata kelola teknologi informasinya sesuai rekomendasi yang sudah ada pada kesimpulan penelitian ini.

Bagi Pemerintah Daerah khususnya dan umumnya Direktorat Pembinaan Kursus dan Pelatihan perlu terus membina LKP-LKP di daerah, agar dalam tata kelola teknologi informasinya akan semakin baik, dalam rangka menuju International Challenge pada tahun 2017.

Dan bagi penelitian selanjutnya Analisis tata kelola teknologi informasi pada Lembaga Kursus dan Pelatihan (LKP) di Kota Kediri dapat digunakan sebagai landasan penelitian dimasa mendatang baik menggunakan domain dan sub domain lainnya, juga obyek penelitinnya difokuskan diarahkan kepada LKP yang berkinerja B atau dianalisis dengan framework COBIT5. 


\section{DAFTAR PUSTAKA}

[1] Gondodiyoto, S., 2007, Audit Sistem Informasi: Pendekatan Cobit, Edisi Revisi, Mitra Wacana Media, Jakarta.

[2] Kania, W. 2011, Pengukuran Tingkat Kemapanan Penerapan Teknologi RFID di Perpustakaan Nasional RI Berdasarkan Framework COBIT 4.1, Tesis, Pascasarjana Insititut Pertanian Bogor.

[3] Herlambang, S., Tanuwijaya, H., 2005, Sistem Informasi Konsep Teknologi \& Manajemen, Graha Ilmu, Yogyakarta.

[4] Putra, I N. B., 2009, Audit Sistem Informasi Perpustakaan Menggunakan Standar COBIT 4.1 Domain Acquire and Implement (Studi Kasus: STIKOM Surabaya), Tugas Akhir, Program Sarjana, Program Studi Sistem Informasi, Sekolah Tinggi Manajemen Informatika \& Teknik Komputer Surabaya, Surabaya.

[5] Information Technology Governance Institute, 2007, COBIT 4.1: Framework, Control Objective, Management Guidelines, Maturity Models, IT Governance Institute, Rolling Meadows.

[6] Sembiring, S. W, 2013, Evaluasi Penerapan Teknologi Informasi Menggunakan Model Cobit Framework 4.1 (Studi Kasus: PT. Prudential Indonesia), Tesis, Program Studi Magister Teknik Informatika Universitas Atma Jaya Yokyakarta.

[7] Sarno, R., 2009, Audit Sistem \& Teknologi Informasi, ITS Press, Surabaya. 